Article

\title{
Evodiamine Stabilizes Topoisomerase I-DNA Cleavable Complex to Inhibit Topoisomerase I Activity
}

\section{Agnes L.-F. Chan ${ }^{1}$, Wen-Shin Chang ${ }^{2}$, Li-Min Chen ${ }^{3}$, Chi-Ming Lee ${ }^{3}$, Chiao-En Chen ${ }^{4}$, Chun-Mao Lin ${ }^{3,5, \dagger, *}$ and Jau-Lang Hwang ${ }^{4, \dagger, *}$}

1. Pharmacy Department, Chi Mei Medical Center, Tainan 710, Taiwan; E-mail: cmh5500@mail.chimei.org.tw (A-F.C.)

2. College of Pharmacy, Taipei Medical University, Taipei 110, Taiwan; E-mail: b507094042@tmu.edu.tw (W-S.C.)

3. College of Medicine, Taipei Medical University, Taipei 110, Taiwan; E-mails: b104094024@tmu.edu.tw (L-M.C.), januslee@tmu.edu.tw (C-M.L.)

4. Institute of Molecular Biology, Academia Sinica, Nangkang, Taipei 115, Taiwan; E-mails: joan1118@imb.sinica.edu.tw (C-N.C.),jh@ccvax.sinica.edu.tw (J.H.)

5. Orthopedics Research Center, Taipei Medical University Hospital, Taipei 110, Taiwan

$\dagger$ These authors contributed equally to this work.

* Author to whom correspondence should be addressed; E-mails: cmlin@tmu.edu.tw (C-M.L.), jh@ccvax.sinica.edu.tw (J-L.H.).

Received: 21 February 2009; in revised form: 13 March 2009 / Accepted: 18 March 2009 / Published: 27 March 2009

Abstract: Evodiamine (EVO), an alkaloidal compound isolated from Evodia rutaecarpa (Juss.), has been reported to affect many physiological functions. Topoisomerase inhibitors have been developed in a variety of clinical applications. In the present study, we report the topoisomerase I (TopI) inhibitory activity of EVO, which may have properties that lead to improved therapeutic benefits. EVO is able to inhibit supercoiled plasmid DNA relaxation catalyzed by TopI. Upon treatment $0 \sim 10 \mu \mathrm{M}$ EVO TopI was depleted in MCF-7 breast cancer cells in a concentration-dependent and time-dependent manner in $0 \sim 120 \mathrm{~min}$. A K-SDS precipitation assay was performed to measure the extent of Top I-trapped 
chromosomal DNA. The ability of EVO to cause the formation of a TopI-DNA complex increased in a concentration-dependent manner, in that the DNA trapped increased by $24.2 \%$ in cells treated with $30 \mu \mathrm{M}$. The results suggest that EVO inhibits TopI by stabilizing the enzyme and DNA covalent complex.

Keywords: Evodiamine; Topoisomerase; Covalent complex.

\section{Introduction}

DNA topoisomerase enzymes regulate the topological state of DNA that is crucial for initiation and elongation during DNA synthesis. Topoisomerase I (TopI) produces a single strand break in DNA, allowing relaxation of DNA during its replication. The single strand break is then religated, thus restoring the DNA double strands. The enzymatic mechanism involves two sequential transesterification reactions [1]. In the cleavage reaction, the active site tyrosine (Tyr723 in human TopI) acts as a nucleophile. A phenolic oxygen attacks a DNA phosphodiester bond, forming an intermediate in which the $3^{\prime}$ end of the broken strand is covalently attached by an $\mathrm{O}^{4}$-phosphodiester bond to TopI tyrosine. The religation step consists of transesterification involving a nucleophilic attack by the hydroxyl oxygen at the $5^{\prime}$ end of the broken strand. The equilibrium constant of the breakage and closure reactions is close to unity, and the reaction is reversible.

Some TopI- and TopII-targeted drugs are reported to stabilize the covalent topoisomerase-DNA complex, thereby preventing religation [2]. The TopI reaction intermediate consists of the enzyme covalently linked to a nicked DNA molecule, known as a "cleavable complex". Covalently bound TopI-DNA complexes can be trapped and purified because the enzymatic religation is no longer functional. Camptothecin (CPT) is a representative drug that targets DNA TopI through trapping a covalent intermediate between TopI and DNA.

The inhibitor-trapped TopI-cleavable complex triggers replication fork arrest and breakage to generate a DNA break that is responsible for the G2/M arrest and activation of DNA damage signals including nuclear factor $\mathrm{\kappa B}$ activation, p53 upregulation, Chk1 phosphorylation, and ATM/ATR activation [3]. The phosphorylated form of DNA-PK increased after treatment with a topoisomerase inhibitor [4]. Topoisomerase inhibitors have been developed for antitumor [5, 6], antiviral [7], antibacterial [8], anti-epileptic [9], and immunomodulation [10] applications.

Evodiamine (EVO), an alkaloidal compound isolated from Evodia rutaecarpa (Juss.), has been reported to possess many physiological functions including vasorelaxation, antiobesity [11], anticancer [12], and anti-inflammatory [13] effects. Evidence showed that EVO induced apoptosis through an accumulation of the cell cycle at the G2/M phase and initiation of apoptosis [14]. The EVO derivatives rutaecarpine, evodiamide, 14-formyldihydrorutaecarpine and dehydroevodiamine, are usually found as contents in preparations [15]. In this study, we report the TopI-DNA trapping activity by EVO, which suggests beneficial effects of EVO for the development of a variety of therapeutic applications. 


\section{Results and Discussion}

\subsection{Growth inhibition of EVO}

The cytotoxic abilities of EVO (Figure 1) and CPT were tested against human breast MCF-7 carcinoma cells, which express high levels of TopI. CPT was used as a reference drug. Both compounds displayed efficient cytotoxicity after $24 \mathrm{~h}$ of drug exposure in the MTT assay. The $\mathrm{IC}_{50}$ values were $3.23 \mu \mathrm{M}$ for CPT and $6.02 \mu \mathrm{M}$ for EVO. EVO was slightly less cytotoxic than CPT against breast MCF-7 carcinoma cells.

Figure 1. Chemical structure of evodiamine.

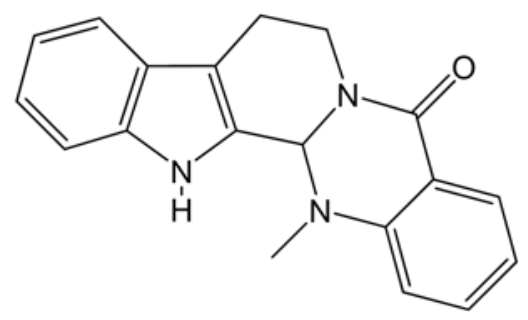

\subsection{Inhibition of supercoiled DNA relaxation from Top I catalysis by EVO}

TopI is known to relax the supercoiled plasmid DNA to an open circular form in vitro and in vivo. CPT and EVO inhibition of supercoiled DNA relaxation in vitro was evaluated. Vaccinia TopI's induction of supercoiled pCDNA3 plasmid relaxation was employed as the assay system, and the results are shown in Figure 2. Supercoiled DNA migrated faster on the agarose gel than the relaxed circular DNA, as shown in the control (Figure 2, lanes 1 and 2). CPT treatments retained a greater amount of uncatalytic supercoiled DNA in a concentration-dependent manner (lanes 3 5, 1 3 $\mu \mathrm{M}$ ). EVO also displayed inhibitory activity on TopI catalytic relaxation in a concentration-dependent manner (lanes $6 \sim 8,1 \sim 3 \mu \mathrm{M}$ ). These results suggest that EVO is able to inhibit supercoiled plasmid DNA relaxation catalyzed by TopI. Using nuclear extract of MCF-7 cells as enzyme source, EVO also showed inhibitory activity on DNA relaxation in a concentration-dependent manner (Figure 2B, lanes $3 \sim 5,1 \sim 3 \mu \mathrm{M}$ ). To further confirm the inhibitory activity on human topoisomerase I (hTopI), recombinant hTopI protein was expressed and purified using the baculovirus expression system (Figure 2C, right panel) for the relaxation assays. Again, EVO revealed inhibitory activity on DNA relaxation catalyzed by hTopI (Figure $2 \mathrm{C}$, lanes $3 \sim 4$ ).

The data reveal that evodiamine is less effective in inhibiting vaccinia TopI than hTopI. Even Vaccinia virus DNA TopI has been reported to be resistant to the effects of camptothecin [16]; it has also been proposed a potential interaction site for camptothecin [17]. With a reduced amount of enzyme in the assay mixture we demonstrated a detectable effect of camptothecin in inhibiting Vaccinia TopI DNA relaxation. 
Figure 2. Inhibitory activity of evodiamine (EVO) on topoisomerase I (TopI). (A) Both camptothecin $(\mathrm{CPT})$ and EVO $(1 \sim 3 \mu \mathrm{M})$ protected DNA from Vaccinia Top I conversion of supercoiled DNA to relaxed closed circular DNA. pCDNA3 $(0.2 \mu \mathrm{g})$ plasmid DNA was incubated at $37{ }^{\circ} \mathrm{C}$ for 30 min with TopI ( 0.5 units) from the Vaccinia virus in the presence or absence of $1 \sim 3 \mu \mathrm{M}$ inhibitors. (B) The reactions with same conditions as adopted in (A) except using nuclear extract (NE) of MCF-7 cells as enzyme source. (C) The same assay conditions as adopted in (A) except using purified recombinant human TopI as enzyme source (left). Recombinant human TopI was obtained using the baculovirus expression system (right, lane 1: cell lysate, lane 2: partial purified fraction, and lane 3: Ni-NTA column purified protein).

A
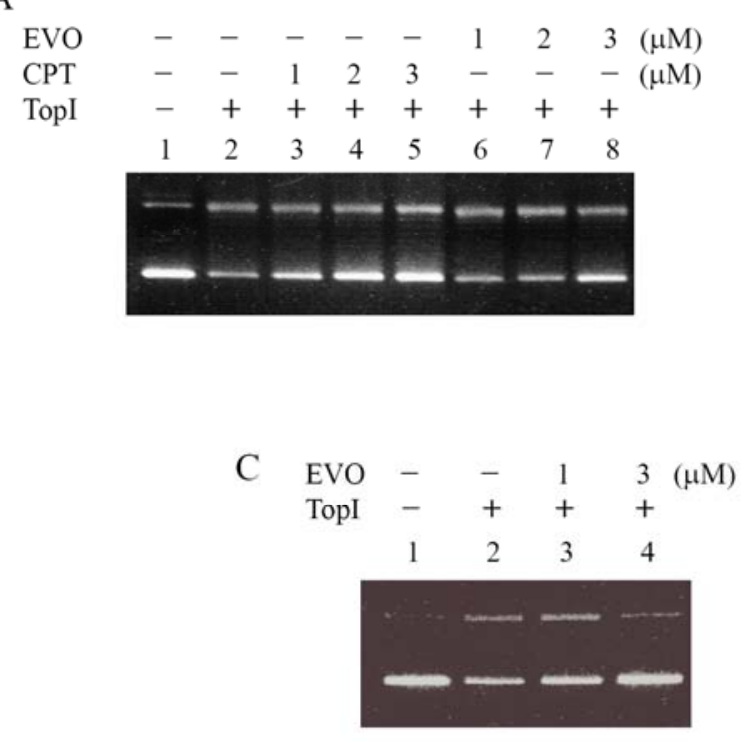

B

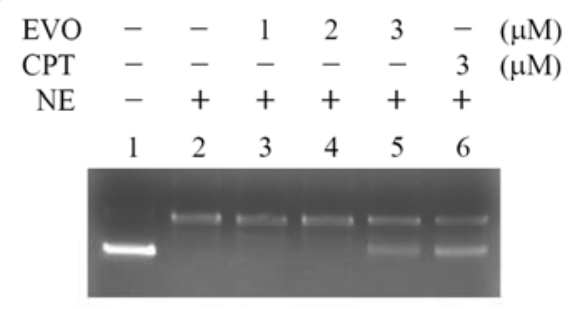

123

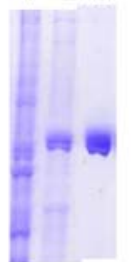

\subsection{EVO depletes the Top I protein}

A depletion assay was performed to confirm the effect of EVO on DNA topological catalysis of TopI. This assay was based on the ability of CPT to trap TopI and DNA to form a CPT-TopI-DNA triple complex, to see if EVO inhibits TopI activity through a similar mechanism. The degree to which depletion occurs depends on the extent to which TopI binds DNA, which is a function of EVO sensitivity. MCF-7 cells maintained in normal conditions expressed a detectable level of TopI protein. MCF-7 cells were treated with EVO for 0 120 min. The protein levels of TopI were examined by immunoblotting. The levels of TopI in EVO treatments $(10 \mu \mathrm{M})$ were depleted in a time-dependent manner, in that the protein level decreased to $<20 \%$ with 120 -min treatment in comparison to the untreated control (Figure 3A). Depletion of TopI protein by EVO was also detected in a concentrationdependent manner after $1 \mathrm{~h}$ of treatment. The relative level of DNA-unlinked TopI protein after treatment with $0 \sim 10 \mu \mathrm{M}$ EVO decreased to $<40 \%$ versus the control (Figure 3B). $\beta$-Actin with constant expression was used as the internal control. 
Figure 3. Topoisomerase I (TopI) depletion by evodiamine (EVO) in MCF-7 cells. (A) MCF-7 cells were treated with EVO $(10 \mu \mathrm{M})$ for $0 \sim 120 \mathrm{~min}$. (B) MCF-7 cells were treated with various concentrations of EVO $(0 \sim 10 \mu \mathrm{M})$ for $60 \mathrm{~min}$. Protein levels of TopI were examined by immunoblotting. $\beta$-Actin with constant expression was used as the internal control.

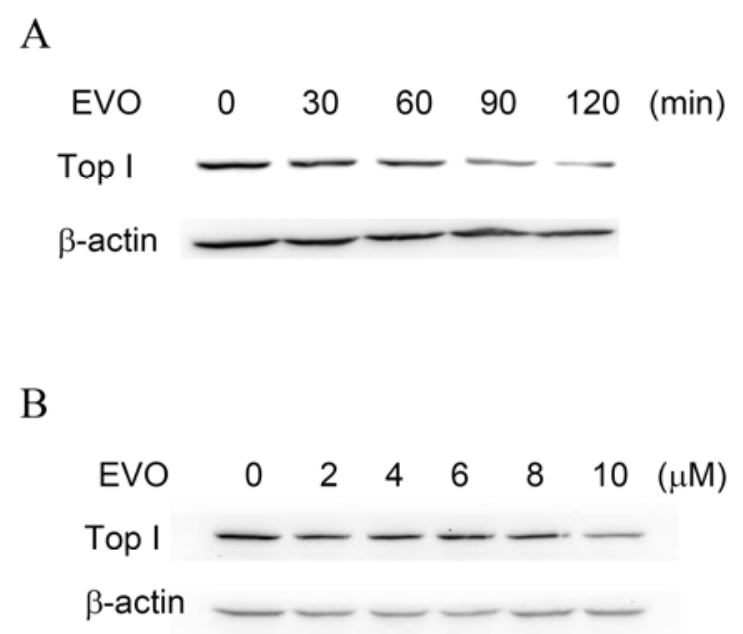

\subsection{TopI-DNA complex-trapping activity in MCF-7 cells}

TopI can be trapped in a covalent complex with DNA by adding protein denaturants. Capturing the covalent intermediate or cleavable complex is difficult because the intermediate has a relatively short lifetime. $\mathrm{KCl} / \mathrm{SDS}$ can precipitate the protein, but not DNA, except when it is linked to a protein. Therefore, the amount of precipitated DNA reflects the EVO-trapping activity. ${ }^{3} \mathrm{H}$-thymidine-labeled cells were treated with $\mathrm{EVO}(0,5,10,20$, and $30 \mu \mathrm{M}$, respectively) for $60 \mathrm{~min}$, and in vivo K-SDS precipitation was performed. Only $3 \%$ of the ${ }^{3} \mathrm{H}$-thymidine-labeled DNA was trapped in a covalent complex with TopI in $0 \mu \mathrm{M}$-treated MCF-7 cells. The DNA trapped by EVO increased to $24.2 \%$ with $30 \mu \mathrm{M}$ treatment (Figure 4). This result indicates that the ability of EVO to cause the formation of the TopI-DNA complex increased with EVO treatment in a dose-dependent manner.

\subsection{Proposed TopI-inhibition mechanism of EVO}

We propose the mechanism of EVO as a TopI inhibitor. TopI catalyzes DNA strand breakage and religation during the procedure of replication and transcription (Figure 5, left panel). The effect of EVO acts by stabilizing the covalent complex between TopI and DNA (Figure 5, right panel), which results in free-form TopI depletion and a barrier to DNA replication and transcription

There are several problems with CPT-derived anticancer agents despite their clinical success. Multidrug resistance (MDR) results from their intracellular concentration being greatly reduced by efflux pumps in a wide variety of tissues which is conferred by P-glycoprotein overexpression [18]. 
Figure 4: Topoisomerase I (TopI)-DNA complex trapping activity of evodiamine (EVO). $3 \mathrm{H}-$ Thymidine-labeled MCF-7 cells were treated with various concentrations $(0 \sim 30 \mu \mathrm{M})$ of EVO for $60 \mathrm{~min}$. K-SDS precipitation was performed to trap the TopI-DNA complex. Radioactivity counts of trapped DNA were determined using a scintillation counter.

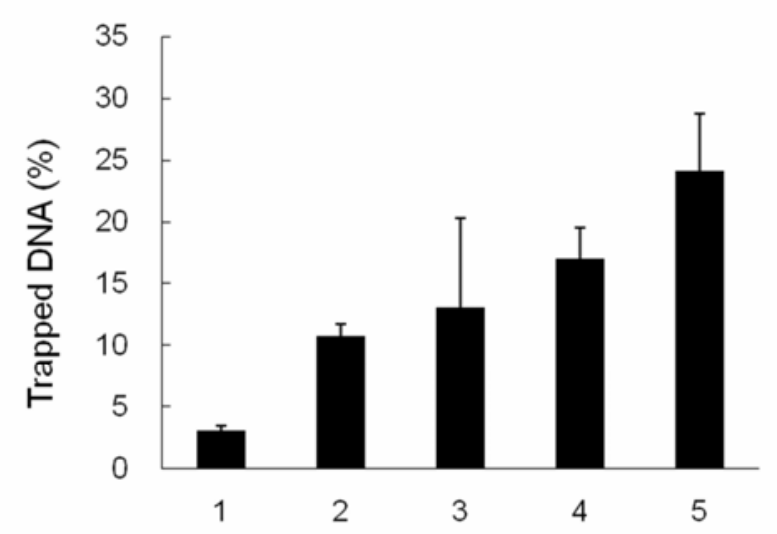

Additionally, all CPTs are substrates for the pump known as breast cancer-resistant protein [19]. EVO isolated from the fruits of Evodia officinalis by Xu et al. did not reveal inhibitory effect on DNA TopI in their assay system [20]. The action of EVO as a TopI inhibitor for anticancer chemotherapy is expected to be greatly enhanced, according to the results of the present study. It may have properties that lead to improved therapeutic benefits to patients with CPT tolerance because EVO has shown anticancer effects in adriamycin-resistant human breast cancer cells [21]. The targeting site of EVO efficacy in the covalent complex remains poorly understood, but studies of the interaction of CPT derivatives have revealed clues to the process, not only due to their structural similarities, but also to the comparable TopI-DNA complex trapping activities.

Figure 5. Proposed mechanism of evodiamine (EVO) inhibition of topoisomerase I (TopI) by stabilizing a covalent complex.
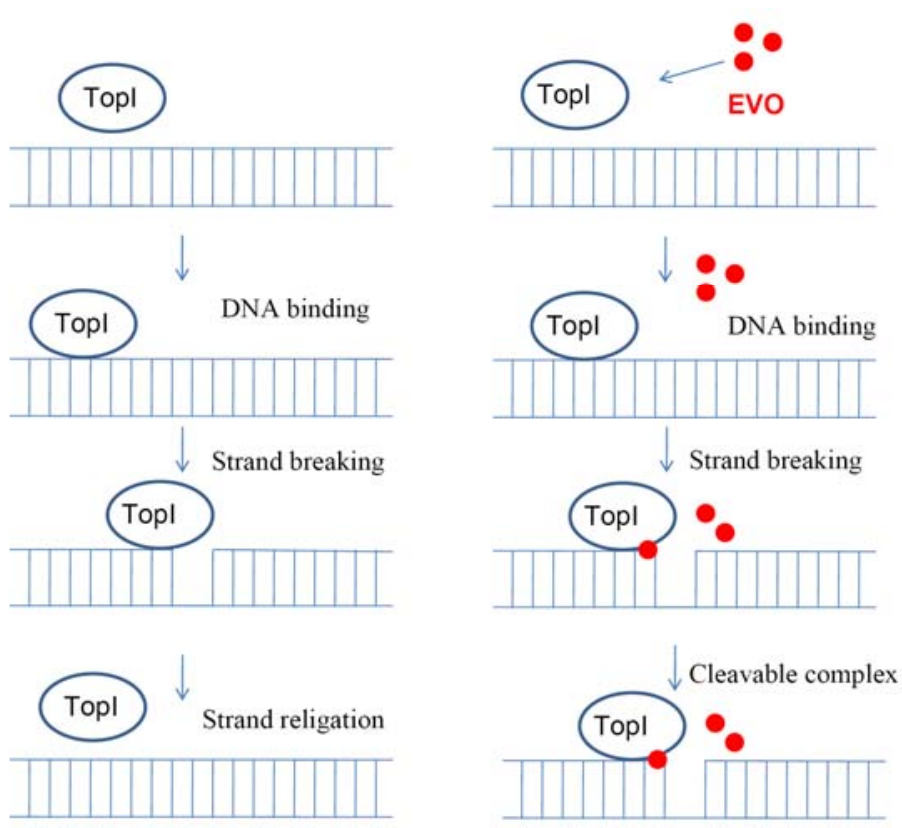


\section{Experimental}

\subsection{Materials}

Recombinant human DNA TopI was obtained using the baculovirus expression system as described [22]. DNA TopI from the vaccinia virus was purchased from Epicentre Biotechnologies (Madison, WI, USA). Evodiamine (purity: $>99 \%$ ) and camptothecin (purity: $95 \%$ ) were purchased from Sigma (St. Louis, MO, USA).

\subsection{Cell culture}

MCF-7 breast cancer cells (ATCC HTB-22) were cultured in Dulbecco's modified Eagle medium (DMEM) supplemented with $10 \%$ heat-inactivated fetal bovine serum (FBS), and $100 \mu \mathrm{g} / \mathrm{mL}$ penicillin-streptomycin. Conditions were maintained at $37{ }^{\circ} \mathrm{C}$ in a humidified $95 \%$ air $/ 5 \% \mathrm{CO}_{2}$ incubator.

\subsection{Preparation of Nuclear Extract}

Human MCF-7 cells $\left(1 \times 10^{7}\right)$ were resuspended in lysis buffer $(400 \mu \mathrm{L}, 10 \mathrm{mmol} / \mathrm{L}$ HEPES [N-2hydroxyethylpiperazine- $N$-2-ethanesulfonic acid], $10 \mathrm{mmol} / \mathrm{L} \mathrm{KCl}, 1.5 \mathrm{mmol} / \mathrm{L} \mathrm{MgCl}_{2}$, and 0.5 $\mathrm{mmol} / \mathrm{L}$ dithiothreitol [DTT], $\mathrm{pH} 7.9$ ) with $0.2 \%$ Nonidet P-40 (NP-40) and protease inhibitor cocktail for $1 \mathrm{~min}$ on ice. After being microcentrifuged for $1 \mathrm{~min}$ at $2,500 \times \mathrm{g}$, the supernatants were collected as cytoplasmic protein extracts. The pellets were washed with lysis buffer without NP-40, resuspended in extraction buffer $(150 \mu \mathrm{L}, 20 \mathrm{mmol} / \mathrm{L}$ HEPES, pH 7.9, $420 \mathrm{mmol} / \mathrm{L} \mathrm{NaCl}, 0.5 \mathrm{mmol} / \mathrm{L}$ DTT, 0.2 $\mathrm{mmol} / \mathrm{L}$ EDTA, and $25 \%$ glycerol), and incubated for $20 \mathrm{~min}$ on ice. After at $12,000 \times \mathrm{g}$ for $10 \mathrm{~min}$, the supernatants were collected as nuclear protein extracts, and aliquots were stored at $-70{ }^{\circ} \mathrm{C}$ until use in relaxation assays.

\subsection{Recombinant human TopI (hTopI) protein expression and purification}

cDNAs encoding full-length hTopI were subcloned into the baculoviral expression vector pFastBac HTa and pFastBac HTc. The bacmid constructs were prepared using the Bac-to-Bac baculovirus expression system protocol (Invitrogen). To express and purify the recombinant hTopI, recombinant baculoviral stock were used to infect $2 \times 10^{7} \mathrm{Sf} 21$ insect cells per 140-mm plate. Infected cells were cultured at $27{ }^{\circ} \mathrm{C}$ for 3 days. The Ni-NTA column/imidazole was used for the hTopI fractionation. Aliquots were stored at $-70{ }^{\circ} \mathrm{C}$ until use in relaxation assays [23]. 


\subsection{TopI-catalyzed supercoiled DNA relaxation}

The inhibitory effect of CPT and EVO on supercoiled DNA strand breakage caused by TopI was evaluated. pCDNA3 plasmid DNA (200 ng) was incubated at $37{ }^{\circ} \mathrm{C}$ for $30 \mathrm{~min}$ in a reaction solution (50 mM Tris-acetate, $100 \mathrm{mM} \mathrm{NaCl}, 2.5 \mathrm{mM} \mathrm{MgCl}_{2}$, and $0.1 \mathrm{mM}$ EDTA; $\mathrm{pH}$ 7.5) in the presence or absence of $0 \sim 3.0 \mu \mathrm{M}$ inhibitor in a final volume of $20 \mu \mathrm{L}$. The conversion of the covalently closed circular double-stranded supercoiled DNA to a relaxed form was used to evaluate DNA strand breakage induced by TopI. Samples were loaded onto a 1\% agarose gel, and electrophoresis was performed in TAE buffer ( $40 \mathrm{mM}$ Tris-acetate and $1 \mathrm{mM}$ EDTA), then the gel was photographed under transmitted ultraviolet light $[24,25]$.

\section{6. $\mathrm{KCl} / \mathrm{SDS}$ precipitation assay of the covalent TopI-DNA complex}

The formation of a cleavable complex in intact cells was quantified by a K-sodium dodecylsulfate (SDS) precipitation technique, a modified procedure described previously by Yoshinari et al. [26]. Cellular DNA was labeled by adding ${ }^{3} \mathrm{H}$-thymidine to the medium to a final concentration of 10 $\mu \mathrm{Ci} / \mathrm{mL}$. After an overnight incubation, cells were plated to a density of $1 \times 10^{5}$ cells/well in a 24 -well plate for another overnight incubation, and treated with various concentrations of EVO $(0 \sim 30 \mu \mathrm{M})$ for $60 \mathrm{~min}$. The medium was removed from each well, and cells were washed with phosphate-buffered saline (PBS) and lysed with $1 \mathrm{~mL}$ of prewarmed $\left(65^{\circ} \mathrm{C}\right)$ lysis solution $(1.25 \%$ SDS, $5 \mathrm{mM}$ EDTA, 0.4 $\mathrm{mg} / \mathrm{mL}$ salmon sperm DNA). Lysate was sheared using a 21 -gauge needle. The samples as background control were treated by the above procedure but with proteinase $\mathrm{K}(400 \mu \mathrm{g} / \mathrm{mL})$ in the lysis buffer, and were incubated at $50{ }^{\circ} \mathrm{C}$ for $2 \mathrm{~h}$. $\mathrm{KCl}(325 \mathrm{mM})$, at $250 \mu \mathrm{l}$, was added to each sample, vortexed vigorously, cooled on ice for $10 \mathrm{~min}$, and centrifuged at 2,500 rpm for $10 \mathrm{~min}$ at $4{ }^{\circ} \mathrm{C}$. The pellet was washed twice in wash solution $(1 \mathrm{~mL}, 10 \mathrm{mM}$ Tris- $\mathrm{HCl}, 100 \mathrm{mM} \mathrm{KCl}, 1 \mathrm{mM}$ EDTA, and $0.1 \mathrm{mg} / \mathrm{mL}$ salmon sperm DNA) and incubated at $65{ }^{\circ} \mathrm{C}$ for $10 \mathrm{~min}$, cooled on ice, then centrifuged at 2,500 rpm for $10 \mathrm{~min}$. The pellet was resuspended in prewarmed $\mathrm{H}_{2} \mathrm{O}\left(400 \mu \mathrm{L}, 65{ }^{\circ} \mathrm{C}\right)$, combined with scintillation liquid $(4 \mathrm{~mL})$ and the radioactivity counts were determined.

\subsection{Detection of the protein levels of TopI}

MCF-7 cells grown in monolayer culture that were $50 \% \sim 80 \%$ confluent were scraped and collected by centrifugation. The cell pellets were lysed in 10 volumes of a 2 x SDS sample buffer ( $20 \%$ glycerol, $10 \% \beta$-mercaptoethanol, $6 \%$ SDS, and $125 \mathrm{mM}$ Tris; $\mathrm{pH} 6.8$ ) and heated in a boiling water bath for 5 min. Samples of each lysate (50 $\mu$ g proteins/lane) were separated electrophoretically in a $7.5 \%$ SDS polyacrylamide gel and electro-transferred to a polyvinylidene difluoride (PVDF) membrane (Immobilon ${ }^{\mathrm{P}}$, Millipore, Bedford, MA, USA).

The membrane was incubated with the primary antibody (rabbit anti-human topoisomerase I polyclonal antisera) [27] at room temperature for $2 \mathrm{~h}$, and then incubated with a horseradish peroxidase-conjugated secondary immunoglobulin $\mathrm{G}(\mathrm{IgG})$ antibody; the immunoreactive bands were 
visualized with enhanced chemiluminescent reagents (Amersham, Buckinghamshire, UK), and photographed using the gel documentation system (UVP, Upland, CA).

\subsection{MTT cell viability assay}

The MTT [3-(4,5-dimethylthiazol-2-yl)-2,5-diphenyltetrazolium bromide] assay to test the cytotoxicity of reagents and cell viability was described previously [28]. MCF-7 cells (5000 cells/well) were grown on a 96-well plate supplemented with DMEM medium (with 1\% FBS) for $24 \mathrm{~h}$. Cells were treated with CPT or EVO $(0 \sim 30 \mu \mathrm{M})$, and the viability was determined by the reduction of MTT. An MTT stock solution (5 mg of MTT/mL of PBS) was added to the growing cultures (at a final concentration of $0.5 \mathrm{mg} / \mathrm{mL}$ ). The OD was measured with a spectrophotometer (Thermo Varioskan Flash, Vantaa, Finland) at $560 \mathrm{~nm}$. A blank with DMSO alone was measured and subtracted from all values.

\section{Conclusions}

EVO is reported to have various pharmacological effects, but this is the first demonstration of EVO as a TopI inhibitor. EVO acts by stabilizing the covalent complex between TopI and DNA during the procedure of TopI-catalyzed DNA strand breakage and religation, which results in a barrier to DNA replication and transcription.

\section{Acknowledgements}

This study was supported by grants from the National Science Council (NSC97-2113-M-038-002) and Taipei Medical University (95CM-TMU-11).

\section{References and Notes}

1. Teicher, B.A. Next generation topoisomerase I inhibitors: Rationale and biomarker strategies. Biochem. Pharmacol. 2008, 75, 1262-1271.

2. Liu, L.F. DNA topoisomerase poisons as antitumor drugs. Annu. Rev. Biochem. 1989, 58, 351375 .

3. Tsao, Y.P.; D'Arpa, P.; Liu, L.F. The involvement of active DNA synthesis in camptothecininduced G2 arrest: altered regulation of p34cdc2/cyclin B. Cancer Res. 1992, 52, 1823-1829.

4. Niina, I.; Uchiumi, T.; Izumi, H.; Torigoe, T., Wakasugi, T.; Igarashi, T.; Miyamoto, N.; Onitsuka, T.; Shiota, M.; Okayasu, R.; Chijiiwa, K.; Kohno, K. DNA topoisomerase inhibitor, etoposide, enhances GC-box-dependent promoter activity via Sp1 phosphorylation. Cancer Sci. 2007, 98, 858-863.

5. Feun, L.; Savaraj, N. Topoisomerase I inhibitors for the treatment of brain tumors. Expert Rev. Anticancer Ther. 2008, 8, 707-716. 
6. Wethington, S.L.; Wright, J.D.; Herzog, T.J. Key role of topoisomerase I inhibitors in the treatment of recurrent and refractory epithelial ovarian carcinoma. Expert Rev. Anticancer Ther. 2008, 8, 819-831.

7. Sadaie, M.R.; Mayner, R.; Doniger, J. A novel approach to develop anti-HIV drugs: adapting non-nucleoside anticancer chemotherapeutics. Antiviral Res. 2004, 61, 1-18.

8. Anderson, V.E.; Osheroff, N. Type II topoisomerases as targets for quinolone antibacterials: turning Dr. Jekyll into Mr. Hyde. Curr. Pharm. Des. 2001, 7, 337-353.

9. Song, J.; Parker, L.; Hormozi, L.; Tanouye, M.A. DNA topoisomerase I inhibitors ameliorate seizure-like behaviors and paralysis in a Drosophila model of epilepsy. Neuroscience 2008, 156, $722-728$.

10. Verdrengh, M.; Tarkowski, A. Impact of topoisomerase II inhibition on cytokine and chemokine production. Inflamm. Res. 2003, 52, 148-153.

11. Wang, T.; Wang, Y.; Kontani, Y.; Kobayashi, Y.; Sato, Y.; Mori, N.; Yamashita, H. Evodiamine improves diet-induced obesity in a uncoupling protein-1-independent manner: involvement of antiadipogenic mechanism and extracellularly regulated kinase/mitogen-activated protein kinase signaling. Endocrinology 2008, 149, 358-366.

12. Ogasawara, M.; Matsunaga, T.; Takahashi, S.; Saiki, I.; Suzuki, H. Anti-invasive and metastatic activities of evodiamine. Biol. Pharm. Bull. 2002, 25, 1491-1493.

13. Ko, H.C.; Wang, Y.H.; Liou, K.T.; Chen, C.M.; Chen, C.H.; Wang, W.Y.; Chang, S.; Hou, Y.C.; Chen, K.T.; Chen, C.F.; Shen, Y.C. Anti-inflammatory effects and mechanisms of the ethanol extract of Evodia rutaecarpa and its bioactive components on neutrophils and microglial cells. Eur. J. Pharmacol. 2007, 555, 211-217.

14. Kan, S.F.; Huang, W.J.; Lin, L.C.; Wang, P.S. Inhibitory effects of evodiamine on the growth of human prostate cancer cell line LNCaP. Int. J. Cancer. 2004, 110, 641-651.

15. Zhou, Y.; Li, S.H.; Jiang, R.W.; Cai, M.; Liu, X.; Ding, L.S.; Xu, H.X.; But, P.P.; Shaw, P.C. Quantitative analyses of indoloquinazoline alkaloids in Fructus Evodiae by high-performance liquid chromatography with atmospheric pressure chemical ionization tandem mass spectrometry. Rapid Commun. Mass Spectrom. 2006, 20, 3111-3118.

16. Shuman, S.; Golder, M.; Moss,B. Characterization of vaccinia virus DNA topoisomerase I expressed in Escherichia coli. J. Biol. Chem. 1988, 263, 16401-16407.

17. Gupta, M.; Zhu, C.X.; Tse-Dinh, Y.C. An engineered mutant of vaccinia virus DNA topoisomerase I is sensitive to the anti-cancer drug camptothecin. J. Biol. Chem. 1992, 267, 24177-24180.

18. Chu, X.Y.; Kato, Y.; Sugiyama, Y. Multiplicity of biliary excretion mechanisms for irinotecan, CPT-11, and its metabolites in rats. Cancer Res. 1997, 57, 1934-1938.

19. Yang, C.H.; Schneider, E.; Kuo, M.L.; Volk, E.L.; Rocchi, E.; Chen, Y.C. BCRP/MXR/ABCP expression in topotecan-resistant human breast carcinoma cells. Biochem. Pharmacol.2000, 60, 831-837. 
20. Xu, M.L.; Li, G.; Moon, D.C.; Lee, C.S.; Woo, M.H.; Lee, E.S.; Jahng, Y.; Chang, H.W.; Lee, S.H.; Son, J.K. Cytotoxicity and DNA topoisomerase inhibitory activity of constituents isolated from the fruits of Evodia officinalis. Arch. Pharm Res. 2006, 29, 541-547.

21. Liao, C.H.; Pan, S.L.; Guh, J.H.; Chang, Y.L.; Pai, H.C.; Lin, C.H.; Teng, C.M. Antitumor mechanism of evodiamine, a constituent from Chinese herb Evodiae fructus, in human multipledrug resistant breast cancer NCI/ADR-RES cells in vitro and in vivo. Carcinogenesis 2005, 26, 968-975.

22. Zhelkovsky, A.M.; Moore, C.L. Overexpression of human DNA topoisomerase I in insect cells using a baculovirus vector. Protein Expr. Purif. 1994, 5, 364-370.

23. Yang, M.; Hsu, C.T.; Ting, C.Y.; Liu, L.F.; Hwang, J. Assembly of a polymeric chain of SUMO1 on human topoisomerase I in vitro. J. Biol. Chem. 2006, 281, 8264-8274.

24. Sekiguchi, J.; Cheng, C.; Shuman, S. Kinetic analysis of DNA and RNA strand transfer reactions catalyzed by vaccinia topoisomerase. J. Biol. Chem. 1997, 272, 15721-15728.

25. Ting C.Y.; Hsu, C.T.; Hsu, H.T.; Su, J.S.; Chen, T.Y.; Tarn, W.Y.; Kuo, Y.H.; Whang-Peng, J.; Liu, L.F.; Hwang, J. Isodiospyrin as a novel human DNA topoisomerase I inhibitor. Biochem. Pharmacol. 2003, 66, 1981-1991.

26. Yoshinari, T.; Yamada, A.; Uemura, D.; Nomura, K.; Arakawa, H.; Kojiri, K.; Yoshida, E.; Suda, H.; Okura, A. Induction of topoisomerase I-mediated DNA cleavage by a new indolocarbazole, ED-110. Cancer Res. 1993, 53, 490-494.

27. Hwong, C.L.; Chen, C.Y.; Shang, H.F.; Hwang J. Increased synthesis and degradation of DNA topoisomerase I during the initial phase of human T lymphocyte proliferation. J. Biol. Chem. 1993, 268, 18982-18986.

28. Lin, H.C.; Tsai S.H.; Chen, C.S.; Chang, Y.C.; Lee, C.M.; Lai, Z.Y.; Lin, C.M. Structure-activity relationship of coumarin derivatives on xanthine oxidase-inhibiting and free radical-scavenging activities. Biochem. Pharmacol. 2008, 75, 1416-1425.

Sample Availability: Not available.

(C) 2009 by the authors; licensee Molecular Diversity Preservation International, Basel, Switzerland. This article is an open-access article distributed under the terms and conditions of the Creative Commons Attribution license (http://creativecommons.org/licenses/by/3.0/). 